\title{
El concepto de persona y la formación sacerdotal*
}

\author{
The concept of person \\ and priestly formation
}

EDISON MOSQUERA**
PP. 21-34

REC: 6/12/2019

ACEP: $10 / 08 / 2020$

\section{Resumen}

La noción de persona es uno de los temas relevantes en el estudio humanístico, desde los griegos hasta la actualidad se le ha estudiado sumariamente y deja valoraciones comprensibles de acuerdo con el momento, de ahí que una clara definición es fundamento para una apreciación objetiva de los individuos. Para llegar a ella, el presente texto desarrolló una revisión bibliográfica de segundo nivel que tuvo en cuenta textos y artículos de investigación en fuentes especializadas. Uno de los elementos que arrojó fue la importancia de destacar la conceptualización medieval de Boecio, ya que esta acompañó el desarrollo antropológico hasta la actualidad. Aunque esto se cuestione, algunos teóricos expresan que esta es la base argumental de la definición. En el ámbito eclesial también tuvo influencia el término y permeó la enseñanza magisterial eclesial, ello obligó a una aproximación en relación con las ciencias humanas para saber dar respuesta a los individuos.

Palabras clave: Persona, personalismo, Boecio, formación sacerdotal. 


\section{Abstract}

The notion of person is one of the relevant themes in humanistic study, from the Greeks to the present it has been studied summarily and leaves understandable assessments according to the moment, hence a clear definition is the basis for an objective appreciation of the individuals. To reach it, this text developed a second-level bibliographic review that took into account texts and research articles in specialized sources. One of the elements that he produced was the importance of highlighting the medieval conceptualization of Boethius, since it accompanied the anthropological development up to the present day. Although this is questioned, some theorists express that this is the argumentative basis of the definition. In the ecclesial sphere, the term also had an influence and permeated ecclesial magisterial teaching, this forced an approach in relation to the human sciences to know how to respond to individuals.

Keywords: Person, personalism, Boecio, priestly formation.

\section{Introducción}

Es común encontrar que en muchas oportunidades el término persona se confunde con la noción hombre o ser humano. Ello entorpece la posibilidad de obtener claridad para un horizonte interpretativo único. Es por esto que una comprensión unívoca del término persona en este tiempo es de difícil consecución. Cabe precisar que todo esfuerzo que se realice para clarificarlo ayuda a configurar un ideal de ser humano como centro del quehacer existencial, así como ayuda a comprenderlo el personalismo.

El presente estudio conceptualiza sobre la noción persona a lo largo de la historia y cómo esta configura una nueva interpretación para entender al individuo. Se tienen en cuenta, además, las posibles variaciones del concepto persona, sin desconocer la postulación medieval de Boecio que alcanzó gran desarrollo en su época e influyó para la configuración antropológica posterior con implicaciones en las ciencias humanísticas. Se utiliza para este ejercicio una investigación bibliográfica de libros físicos y artículos de investigación virtual para recopilar datos e informaciones descriptivas del tema que atañe y permiten contextualizar el término en sus fundamentos y precisión de las variaciones presentadas en su desarrollo.

Es importante tener presente para lo anterior si la noción de persona a lo largo de la historia ha tenido algún tipo de resignificación y cuál ha sido su influencia en las ciencias humanas, para comprender las ciencias que intervienen en la búsqueda de su realización, especialmente en las eclesiales.

\section{Método}

Para el desarrollo del presente estudio se utilizaron fuentes bibliográficas físicas y artículos de investigación virtuales en idioma castellano. La temporalidad de los textos físicos fue variada y se consultaron en la biblioteca universitaria de Unicatólica, Cali, Colombia. Los artículos de investigación virtual examinados datan de los últimos cinco años (2015-2020) de revistas especializadas. Su búsqueda se hizo mediante Google académico con palabras clave como: persona, individuo, personalismo, bioética y formación sacerdotal. En los resultados arrojados se evaluó pertinencia, fiabilidad y validez de la información. De las fuentes consultadas se eligieron 21 entre texto físico y artículos virtuales, estos ayudaron a la conceptualización del presente escrito.

Se analizó la noción de persona, su historia y desarrollo y la manera en la que este término se configuró en los diferentes periodos. También se abordo su presencia 
en la formación sacerdotal para concientizar quién es el destinatario de la cura de almas.

\section{Noción de persona}

El término persona se emplea usualmente en la cotidianidad, no obstante, a pesar de su reiterado uso, es difícil establecer precisiones que ayuden a dar un significado absoluto al término. Diversos autores que se han enfocado en la conceptualización de esta palabra presentan notorias disimilitudes en lo que sostienen y más allá de entablar una discusión sobre dichas discrepancias, se persigue obtener el mayor número de elementos teóricos que permitan abordar a la persona como objeto de estudio.

El término latino persona, per-sonare, llegó al ámbito filosófico gracias a la escuela estoica a través del significado de mascara. Per-sonare significaba resonar la voz. La raíz terminológica se formó a partir del griego

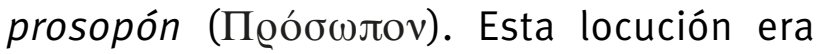
muy usada en el teatro griego, con ella se indicaba la máscara que utilizaba un actor en el teatro para representar un personaje, sobre todo en la tragedia. También significaba la apertura por la cual salía la voz del actor en las representaciones que escenificaban. Cabe destacar que "en su origen, la etimología no indicaba los rasgos esenciales del rostro, sino el esconderse del rostro del actor" (Sgreccia, 2013).

Como se observa, el término persona se remonta a la época griega, allí se encuentra su raíz. Ya en el ambiente cristiano la noción de persona se elabora a partir de términos teológicos, en muchos momentos por analogía con concepciones antropológicas. Cabe destacar que en la "escolástica se habló de las personas divinas; más aún, la palabra se aplicó más a Dios que al hombre" (Sánchez García, 2016). Aunque resulta arriesgado definir la persona desde postulados de bases espirituales, puede resultar ilustrativo tener algunos fundamentos al respecto.

Con el Concilio de Nicea se dio un cambio, ya no se utilizó la palabra prósopon, se implementó el término npostasiz (hipóstasis: sustrato, soporte, supuesto). Este término griego que se propone en un ambiente de discusión sobre cuestiones con respecto a la Trinidad tiene como problema central el debate sobre "la cuestión de la relación entre 'naturaleza' y 'persona' en Cristo" (Ferrater Mora, 2002, p. 2760). Bajo el enfoque cristiano, el concepto de persona adquiere una orientación diferente al que se ha descrito de la cultura griega. Hasta este punto es factible mencionar que, más allá de la cuestión de tipo histórico, con el cristianismo se dio apertura al desarrollo de una concepción diferente a aquella que es meramente de corte etimológico.

En respuesta a esto, la definición del Concilio determinó que Cristo es una única persona, en él se da una única identidad, la de hijo con dos naturalezas: la divina y la humana. A partir de allí es importante entender que el concepto de "dignidad de la persona" es una elaboración teológico-medieval que busca definir el misterio cristológico, y que postula cómo dos naturalezas se unen en la persona divina (Cf. Farrel, 1991).

Durante la época medieval el concepto cristiano de persona se instauró en el contexto cultural del momento, el cual, con el transcurrir de los siglos se fue modificando de acuerdo con el surgimiento de nuevas posturas que, más allá de antagonismos, en cada época proporcionan los elementos que lo buscan conceptualizar con mayor precisión.

Entre las definiciones más importantes del concepto de persona propuestos se 
encuentra la postulada por Severino Boecio en el ambiente medieval. Esta proposición se encuentra en el capítulo tercero del texto Sobre la persona y las dos naturalezas, en él expresa "Personae est naturae rationalis individua substantia", es decir que "la persona es una sustancia individual de naturaleza racional” (Burgos, 2013, p. 30).

Por su parte, Boecio apela a la filosofía aristotélica para clarificar el concepto, toma la proposición de "sustancia individual" y el de “naturaleza racional”. Para la primera proposición, Aristóteles utilizó el término al menos en cuatro sentidos: la esencia, lo universal, el género y el sujeto "aquello de lo cual se predican los otros; en cambio él no se predica nunca del otro [...] Por eso [...] parece ser la sustancia primera por excelencia” (Rovetta Kliver, 2008, p. 197). De la segunda proposición realizada en la Metafísica de Aristóteles, se encuentra la referencia a la forma, es decir que, por la racionalidad, expresa el texto "todos los hombres desean por naturaleza saber", lo que le confiere al individuo la capacidad de "abrirse al horizonte irrestricto de lo otro y los otros, es decir, de autotrascenderse" (Barrio, 2007).

En contraste con la lógica aristotélica, Boecio desarrolla su propio concepto a través de una serie de ideas que de manera detallada describe y categoriza. Con él se abre un nuevo panorama conceptual frente las conceptualizaciones existentes. Cabe resaltar que la definición de Boecio es más completa que la de Aristóteles:

Siguiendo la definición de Boecio, la persona humana no designa principalmente a una esencia humana expresada en el concepto universal de "animal racional", sino más bien se refiere a este hombre singular, pues la definición de persona de Boecio está designando a un modo de ser substancial individual con toda su concreción, que se realiza singularmente como naturaleza racional, con lo cual, si se define a la persona como substancia individual de naturaleza racional, no se está definiendo una esencia abstracta universal, sino un modo de subsistir concreto: "Así, el nombre de individual entra en la definición de persona para indicar el modo de subsistir propio de las substancias particulares". (Ramos Rosere, 2015)

La definición de Boecio exalta tres aspectos esenciales del ser humano: la sustancialidad, la individualidad y la naturaleza racional. La persona es un ser que vive su mismidad (sustancia individual) para adentrarse en una alteridad (naturaleza racional). Esta doble cara es la que expresa la particular relación consigo mismo (individualidad) y con el entorno que le rodea para aprehenderlo. Para Boecio, se da persona en quien posee racionabilidad y entendimiento.

Durante la época medieval se encuentra un nutrido número de autores que generaron propuestas de significación a la noción de persona desde el postulado de Boecio, este se convirtió en una propuesta casi rigurosa para explicitarla.

Santo Tomás de Aquino siguió el mismo postulado de Boecio "Personae est naturae rationalis individua substantia", noción que valoró en el campo antropológico. En ella "el hombre era persona y ser persona significaba poseer una naturaleza racional subsistente individualmente" (Burgos, 2013, p. 30).

\section{Santo Tomás expresó en Suma Theologica} (I, q. 29, a.3) que "magnae dignitatis est in rationali naturae subsistere", con lo que apuntaba a la gran estima que en el ambiente cristiano se tiene por la noción de persona. Esto hace que en el ambiente cristiano se mire el aspecto de la dignidad que le viene implicada a la valoración del concepto de persona. En el texto mencionado el término 
persona se empezó a unir al de "dignidad" y hacía referencia a algo sobresaliente, por eso

La palabra "dignidad" hace alusión, fundamental y primariamente, a la "preeminencia", a la "excelencia" (de excellere: destacar). Digno es aquello por lo que algo destaca entre otros entes, en razón de [sic] un valor que le es propio. Con lo cual, la expresión "dignidad de la persona" que actualmente se usa, destaca en la persona un carácter que le es resaltante y exclusivo s[o]lo de ella. Algunas corrientes antropológicas centradas en la persona han interpretado el concepto como la valoración de la persona humana como fin que vale en sí misma, ya que "digno" es aquello que debe ser tratado con "respeto", es decir, "con miramiento" (respetus), con veneración. De ahí que, en rigor, hablar de la dignidad de la persona resulte un pleonasmo, o se trate quizá de una redundancia intencionada para resaltar o subrayar la altura del rango que ocupa ese tipo de entes en el orden del universo que son las personas. (Ramos Rosere, 2015)

Como ya se mencionó anteriormente, la época medieval recogió la definición de Boecio y la aceptó sin proponer un desarrollo posterior al concepto, la racionalización del individuo como ser personal radicó en que este puede elegir entre lo bueno y lo malo, juicio capacitado por su capacidad de elección y responsabilidad. La estima por la persona es alta y se le entiende como "un tipo especial de sustancia” (Burgos, 2013, p. 31), sea que se refiera a Dios o al hombre.

Ya a finales de la Edad Media, el "término se gramaticalizó con un sentido donde se incluye el significado: uno y la gente con el que fue utilizado en esta época y se preserva hasta nuestros días" (Zavala, 2010), con lo que se puede afirmar que el uso del vocablo se popularizó.

El termino de persona no se quedó como objeto de estudio únicamente en el ámbito teológico, también entró el término en el ambiente filosófico, esto contribuyó a ampliar la conceptualización con respecto a su significado, a partir de los postulados de la razón sin una acentuada influencia religiosa. Es importante tener presentes algunas concepciones de la modernidad y con ello, la significación alcanzada, cabe resaltar que este periodo privilegió la actividad racional sin mostrar mayor importancia sobre el sujeto metafísico.

Un importante autor de la modernidad es Descartes, para este el concepto de persona se identifica con el "yo" como autoconciencia de sí. Así, "con el yo que se pone en relación consigo mismo mediante la conciencia y el conocimiento de sí" (Sgreccia, 2013); la persona adquiere "el carácter reflexivo y pensante propio de la defensa que se hace del pensamiento en la época" (Zavala Olalde, 2010). Con esto se subraya el carácter relacional de la persona y alcanza gran importancia la dimensión ética de este, se destaca así su valor y dignidad en la nueva reflexión sobre el hombre que paulatinamente tomó distancia del teocentrismo.

Hasta Descartes el concepto de persona partió de la contemplación mental y su descripción se basa en la experiencia del hombre. En contraposición, surgió un enfoque que intenta conceptualizar a la persona desde lo empírico. Este hecho implica una dualidad en la conceptualización.

El empirismo "socava la consistencia ontológica de la persona humana identificando el Yo con la experiencia psíquico-perceptiva” (Sgreccia, 2013). El empirismo negó el yo del racionalismo, ya que lo propuso como una construcción de la mente que garantiza la percepción de sí. El empirismo identificó a la persona "con la misma experiencia subjetivo-perceptiva y la sucesión de ideas" (Sgreccia, 2013). 
Con ello postuló que el yo no es elemento de conciencia, debido que la mente no es el lugar asociado a las sensaciones.

La filosofía kantiana acuñó el término persona unido al de dignidad, como un agente racional y moral; la persona es el ser fin en sí, lo que le faculta para dictarse sus propias leyes, que sea autónomo, pero todo ello desde los postulados de la razón, por eso se puede decir que "el modelo kantiano de dignidad parece reconocer un valor interno y absoluto al ser humano debido a su humanidad. Este reconocimiento implica un deber de respeto que deben seguir los individuos en sus relaciones con los demás y consigo mismo" (Pele, 2015).

Siguiendo el hilo conductor de la historia $y$, antes de pasar a la posmodernidad, cabe resaltar que el racionalismo y empirismo "están en el origen de las concepciones antropológicas que reducen el concepto de persona humana" (Sgreccia, 2013). La absolutización de ambas tendencias propició la marginación y reducción del término persona, lo cual influyó en la noción posterior del concepto. Se encuentra así que "la posmodernidad plantea una multiplicidad de perspectivas, la fragmentación del pensamiento, una amplia gama de enfoques y voces" (Ruiz, 2010, p. 177). Debido a lo anterior se podría decir que lo que estaba establecido medianamente quedó diluido en un mundo que perdió sus referentes.

La posmodernidad dejó el concepto de persona sin fundamentos sólidos, dada la multiplicidad de concepciones quedó perdido el referente etimológico que le antecedió. En sí, el concepto de persona no posee una connotación concreta respecto de sí, se cuestiona el referente de significación e identidad que se posee.
El siglo XX constituye el escenario de pugna entre dos grandes ideologías: el colectivismo y el idealismo. De ellos, es importante postular cómo el colectivismo promueve valores generales de la sociedad, en detrimento de los individuos; el hombre es parte del todo por el que debía sacrificarse si así fuera necesario. El individualismo patrocinó la postura contraria, la valoración del individuo por encima de la sociedad, la manifestación propia de este individuo resultó ser la insolidaridad que se vale de los medios económicos y de la inteligencia para alcanzar sus fines (Burgos, 2013).

En el posmodernismo la persona se hizo importante en cuanto a los intereses de sectores sociales, los que ponen enfasis en beneficios asociados al poder y a situaciones que ayudan a mantener el status quo del contexto. En este punto, hablar de persona es hacer frente a discuciones sobre la importancia y el lugar que tiene el sujeto dentro de su espectro social y cómo esta importancia le otorga más o menos beneficios en una colectividad.

Se puede entender la posmodernidad como un tiempo que derogó los modelos y fundamentos sobre los cuales concebir una noción clara de persona; ello puede llevar a la conceptualización de que este tiempo: "constituye una mutación sociológica global [...]. Se caracteriza por ser una época y una cultura que ha perdido la fe en la razón" (Prats Mora, 2012, p. 83, énfasis añadido). Otro aspecto a considerar es que durante este periodo se presentaron dos guerras mundiales y un gran número de conflictos entre países, situaciones relacionadas con el deseo de imponer totalitarismos, de allí que el individualismo se entienda como el elemento ideológico del capitalismo salvaje de finales del siglo XIX y comienzos del XX (Cf. Burgos, 2013). 
La compleja situación que afronta la humanidad propicia una recuperación de la noción de persona. Las guerras mundiales fueron el elemento decisivo en ese cambio ideológico, con esto se encuentra que "lo importante era la persona, cada persona concreta e individual y no las abstracciones. Y si la filosofía quería responder a la realidad y ser útil tenía que articularse en torno a ese valor esencial” (Burgos, 2013, p. 36). Ese recuperar el sentido por la persona, sobre todo por los hechos que cosificaron al hombre, llevan a consolidar una filosofía que reelabora su concepción.

El nuevo postulado filosófico sobre la persona que reelaboró el concepto se denominó personalismo, sin embargo, algunos teóricos del tema expresan que este saber no es nuevo, tiene raíces en postulados que se pueden encontrar en las enseñanzas del Medioevo, por ello se puede expresar que el personalismo:

Posee una fundamentación especulativa que hunde sus raíces en el personalismo contemporáneo y medieval, y con ello, en una tradición filosófica rigurosa, que breva de hombres tan variados como Agustín de Hipona, Alejandro de Hales, Tomás de Aquino, Buenaventura de Bagnoregio, Immanuel Kant, Max Scheler, Emmanuel Muller, Dietrich von Hildebrand, Karol Wojtyla, Rocco Buttiglione o Josef Seifert. (Tomás y Garrido y Postigo, 2007, p. 39; Cf. Lleras, 2019)

El postulado personalista engloba amplias discrepancias con ideologías utilitaristas, centra a la persona como objeto de estudio, más allá de la filosofía como mera práctica reflexiva; ahora queda implicada una antropología existencial para desarrollar un concepto de persona profundo que considera diversas perspectivas y contextos.

El personalismo sostiene "el valor superior de la persona frente al individuo, a la cosa, a lo impersonal. El personalismo se opone, pues, tanto al individualismo como al impersonalismo" (Ferrater Mora, 2002, p. 2764). El surgimiento de este es entonces remedio en la "lucha ideológica entre el individualismo y los colectivismos; necesidad de que la nueva antropología de la persona asumiera las aportaciones de la Modernidad: conciencia, sujeto, yo, libertad, dinamicidad, etc." (Burgos, 2013, p. 37). Uno de los grandes aportes fue que todo el contenido se postuló desde una ideología asentada en la vivencia antropológica con apertura a lo ontológico.

Como se ha descrito, a lo largo de la historia gran diversidad de autores, teorías y posturas ideológicas han abordado el concepto de persona, se pueden clasificar en posturas de corte teológico y filosófico, ellas brindan un panorama ecléctico capaz de ofrecer una perspectiva integral de significación al concepto.

\section{Persona, concepto de difícil definición}

No resulta sencillo definir a la persona, solo se pueden llegar a aproximaciones de esta.

La mejor definición dado es quizás la de Severino Boecio ya mencionada: "persona es la sustancia individual de naturaleza racional". Cabe tener presente que la definición de Boecio tiene sus límites para la concepción de persona en la actualidad, pues esta "se trataba de una definición brillante, genial para su tiempo, pero insuficiente" (Burgos, 2013, p. 40; Boluarte, 2018). El concepto de persona en la actualidad debe tener en cuenta lo cambiante del mundo de hoy.

Lo anterior deja abierta la pregunta sobre si existe una definición precisa para el concepto de persona, lo que no para posible cumplir con esas características. 
El personalismo rechaza esa posibilidad de definición, ya que la persona es un ser complejo de comprender, y ello.

[...] puede conllevar el peligro de que, si algo no aparece en la definición, no se estudie o no se le dedique suficiente atención [...] y, por eso se ha preferido optar por sistemas abiertos que no excluyan la posibilidad de añadidos 0 complementos” (Burgos, 2013, p. 42).

Con esto se quiere dar una explicación del hombre con aperturas a su comprensión, el personalismo postula las principales notas que caracterizan a la persona con las siguientes notas fenomenológicas para las cuales se acude a aquellas presentadas por Burgos (2013, pp. 44-47):

1. Substancialidad-subsistencia: la persona es siempre la misma, aunque cambie el mundo a su alrededor y ella también cambie.

2. Intimidad-subjetividad: la persona se concibe como un ser autónomo, consciente de sí e independiente, es decir, como un alguien, un sujeto, un "yo" capaz de decidir sobre sí mismo y ponerse frente al mundo.

3. Ser corporal, espacial y temporal: la persona posee una dimensión material corporal, además es subjetividad e intimidad. Ella se mueve en el espacio físico y geográfico, por ello no es un ser estático, sino en constante evolución.

4. Apertura y definición: todos los hombres necesitan salir de sí y actuar en pos de y para otros. Esto para realizarse en plenitud, fundamentalmente, de sus capacidades y facultades más elevadas y espirituales: la afectividad, la inteligencia y la libertad.
5. Hombre y mujer: existen dos tipos o modalidades diversas de persona humana: el hombre y la mujer. No existe persona humana en abstracto, sino personashumanasmasculinasopersonas humanas femeninas que aportan una maravillosa diversidad cuajada de misterio y complementariedad.

Las notas fenomenológicas apuntan a una dirección precisa: la persona humana es un ser que tiene una dignidad, un valor que está por encima de las cosas. La dignidad humana es aquella condición especial que reviste todo ser humano por el hecho de serlo; lo caracteriza de forma permanente y fundamental desde su concepción hasta su muerte. La dignidad humana es aquello que hace única e irrepetible a cada persona, característica innata del ser humano como valor absoluto.

La concepción de dignidad humana desde el personalismo predica que la persona, en cuanto sustancia, tiene autonomía, no como integrante de una especie o de una sociedad, es decir que no se puede considerar como parte de un todo. En consecuencia, nadie tiene derecho a disponer de la persona, al contrario, su autonomía se debe respetar.

La persona en cambio, por su libertad y razón, es capaz de superar el dato meramente natural y de trascenderse a sí misma para construir su existencia mediante el ejercicio de su libertad. Esto incluye dominar y poner a su servicio el mundo natural.

Por lo anterior, la persona como misterio es una construcción continua, todo lo que se haga por ella debe propiciar la "modificación del estatuto ontológico, religioso y social; una nueva vida social que implica un cambio radical en el comportamiento, una nueva actitud 
ante la vida y el cosmos" (Ries, 1994, p. 18). Acciones que no lleven a esta meta no cumplen con su tarea, ya que se estaría cosificando a la persona y la tarea por construir al individuo no está cumpliendo con su fin.

Benedicto XVI definió a la persona como "una unidad articulada de tres dimensiones: somática, psíquica y espiritual" (Prats Mora, 2012, p. 20), con ello se puede concluir que una clara noción del individuo buscaría propiciar un sujeto integral en el que exaltasen las notas fenomenológicas expuestas anteriormente.

La imposibilidad de definir a la persona expresa la riqueza contenida en ella, eso demuestra misterio y don, misterio en cuanto desconocimiento y don en cuanto apertura y posibilidad de nuevas expectativas.

\section{La formación sacerdotal y el concepto de persona}

Respecto a la formación del Concilio, el Vaticano II "insiste en una formación científica amplia, tradicionalmente eclesiástica, sin que se deseche por ello mismo un sano humanismo" (Sala Balust y Hernández Salamanca, 1966, p. 174); se inculca la preocupación por el estudio de la filosofía escolástica, de la Sagrada Escritura, el Catecismo, liturgia, pastoral, pedagogía, música sacra, cuestiones sociales, entre otras áreas de conocimiento.

La formación en los seminarios es un puente articulador de la enseñanza de la tradición eclesial y sus aproximaciones a las vivencias contemporáneas para consolidar las nuevas maneras de ver la vida y la acción de Dios en la historia.

La escolástica ha estado presente en el pensamiento y en la manera de pensar de la
Iglesia, esta "no es otra cosa que la aplicación del pensamiento deductivo a los datos de la revelación cristiana" (Hertling, 2006, p. 221). La especulación filosófica y teológica se desarrolla en el siglo IX, especialmente en las escuelas catedralicias, abadías, monasterios y posteriormente, en las universidades (Cf. Sala Balust y Hernández Salamanca, 1966). En la actualidad, la formación sacerdotal se realiza en espacios especializados y destinados a la enseñanza de la filosofía y teología: seminarios, universidades. Ello permitió la consolidación de una enseñanza acorde a la historia eclesial en relación con el mundo presente.

La escolástica logró articular todo el proceso formativo en filosofía y teología; razón y fe, los son temas centrales de este tiempo. Estos se extendieron a lo largo de toda la Edad Media, por eso se puede comprender que "la escolástica no es una filosofía, sino un espíritu, un método, una forma de hacer filosofía" (Goñi, 2010, p. 74). Como método, ha estado presente en la manera de enseñar y acompañar a los futuros candidatos a las órdenes sagradas.

En la actualidad el sistema de enseñanza escolástica sigue vigente de una u otra manera. La forma de enseñar en los seminarios recoge esta vivencia. El quehacer de esta enseñanza es llevar al individuo a la comprensión de los contenidos de la fe. Según el Reglamento General del Seminario Diocesano de Vitoria, los seminarios

[...] son colegios donde la Iglesia recoge a los jóvenes elegidos por Dios para el sacerdocio, con el fin de preservarlos de los malos hábitos del mundo, educarlos religiosamente e instruirlos en las ciencias eclesiásticas y profanas, como mejor conduzca al digno desempeño de la formación sacerdotal. (Martín Hernández y Martín de la Hoz, 2014, p. 221) 
El hecho de apartarlos en lugares especiales tiene como intensión que, alejados de la realidad, puedan discernir la manera de enfrentarla sin verse inmersos en ella; se busca objetividad para actuar y acompañar a quien se acerca en busca de direccionamiento. El sistema escolástico otorgó a la Iglesia una estructura de pensamiento para analizar y estudiar los temas teológicos gracias a todos los aportes filosóficos de la antigüedad.

Con el paso del tiempo y gracias a otras disciplinas (psicología, antropología, sociología, medicina, etc.) la Iglesia logró articular su pensamiento con los nuevos contextos en los cuales se desenvuelve. Las discusiones dejaron de ser cuestiones de índole dogmático-doctrinal para adentrarse en problemas que aquejan a la sociedad y especialmente a la persona humana, entre ellos se pueden mencionar cuestiones de pobreza, violencia, existencia, etc. (Cf. Hertling, 2006).

En la actualidad se cambió la preocupación por temas del ser íntimo de Dios para preguntarse y responder sobre cómo actúa Dios en la humanidad, además, cuál ha sido su presencia en esta. En otras palabras, las preguntas se formulan ahora desde los postulados del "qué”, “cómo”, “cuándo”, "dónde” y "con qué", se deja así de lado la pregunta del "por qué" de las cosas.

Resulta conveniente hacer un salto a la vida de los seminarios del siglo XIX. En ese tiempo "los seminarios estaban divididos en gramáticos o retóricos, filósofos o artistas, teólogos moralistas. El seminarista, durante doce años, debía asistir puntualmente a las clases, además de a las conferencias, academias o sabatinas los jueves, sábados o domingos" (Martín Hernández y Martín de la Hoz, 2014, p. 199) Resulta evidente que durante este tiempo no solo importaban las asignaturas que pudiera recibir el candidato al sacerdocio, también era importante que la persona fuera un excelente cura de almas y un eclesiástico ilustrado.

El siglo XX propició una visión integral e integrante de la formación sacerdotal. En ese entonces al clero "se le quiso dar una preparación más esmerada por medio de la renovación de los seminarios y mediante la creación de las universidades eclesiásticas" (Martín Hernández y Martín de la Hoz, 2014, p. 209), también mediante la conformación de facultades de Teología cuya misión revistió la formación específica de los futuros clérigos.

Los seminarios mayores son necesarios para la formación sacerdotal, por lo que la educación de los alumnos debería de ir encausada hacia una formación de verdaderos pastores de las almas, con el ejemplo de Jesucristo, maestro, sacerdote y pastor. Por lo tanto, todos los aspectos de la formación: espiritual, intelectual y disciplinar, se han de apocar conjuntamente a esta acción pastoral. Por otra parte, en el numeral 13 de la Optatam totius del Concilio, Vaticano II expone que los futuros clérigos "han de tener la formación humanística y científica que permite a los jóvenes en su nación tener acceso a los estudios superiores".

De todas las áreas de estudio en la formación sacerdotal existen dos líneas que pueden interesar para el fin específico de este trabajo. En primera instancia está la línea filosófica y en ella todo el estudio humanístico, en especial desde la ética y antropología, ellas pueden ayudar a comprender y dar respuesta a quién es la persona y su comportamiento en el mundo. La otra línea de interés es la que compete a la teología moral y desde esta, todo lo que se relaciona con la materia moral de vida, más específicamente en lo que compete a la bioética. 
Es relevante postular que en su orientación doctrinal la Iglesia señala que la bioética es un área de estudio importante, ella ayuda a responder las preguntas de carácter técnico, científico, de responsabilidad social, moral y existencial en las que está implicado el desarrollo y vida de las personas.

\section{Formación sacerdotal y bioética}

La bioética es un campo de estudio de gran interés sobre la vida humana en la enseñanza magisterial eclesiológica, realidad que no es ajena para la formación sacerdotal. A través de ella "la Iglesia católica se vale de la razón y de la fe, contribuyendo así a elaborar una visión integral del hombre y de su vocación" (Congregación para la Doctrina de la Fe, 2008, p. 7). Toda la preocupación por el hombre propiciada por la Iglesia está en función de superar la cosificación del individuo.

Como ya se explicitó anteriormente, la idea de persona es uno de los grandes aportes del cristianismo a la civilización, asimismo es una concepción difícil de definir, puesto que implica imponer ciertos límites, esto porque

[...] cada persona humana, en su irrepetible singularidad, no está constituida solamente por el espíritu, sino también por el cuerpo, y por eso en el cuerpo y a través del cuerpo se alcanza a la persona misma en su realidad concreta. (Sarmiento, 1987, p. 487)

Esta noción de persona está fuertemente sustentada en la bioética desde el postulado personalista, puesto que al tomar en consideración los principios de esta, "la búsqueda de la competitividad desde una visión humanista es promover actitudes como el respeto por la integridad física y el valor de la vida humana, el servicio, la responsabilidad y el bien común" (Yacarini-Martínez, 2019). Es evidente que de esta forma se promueve a la persona para su libertad y responsabilidad, se le impulsa a su autorreconocimiento para que sea partícipe del mundo social y alcance así su desarrollo integral.

En toda su enseñanza la Iglesia tiene clara su misión y preocupación en pro de la vida del hombre, de cuál es su destino y qué le es viable o no. Producto de ello, a lo largo de los años se ha pronunciado a favor y en pro de la defensa de la persona en pos de su respeto y valoración en todas las etapas de desarrollo.

Un posible ejemplo sintético de lo anterior es la instrucción Donum Vitae de Juan Pablo II que se refiere al respeto de la vida por nacer y la dignidad que tiene la procreación. Este documento busca sentar las bases para el respeto de la vida humana desde sus inicios, en él se resalta el valor de la procreación natural como medio para la clara conceptualización de lo que es ser persona. Se puede entender que la "tecnificación" del inicio de la vida puede cambiar la noción que se posee de persona y su relación con el mundo. En el prólogo de este texto, como postula el libro Bioética y religión, "la razón para oponerse a una determinada tecnología no es por ser artificial si no en la medida en que vulnere la dignidad de las personas" (Masiá, 2008, p. 27); ir en contra de la dignidad del individuo es mutar su valoración ontológica.

En el 2008 la Congregación para la Doctrina de la Fe publicó el documento Dignitas Personae que trata sobre algunas cuestiones de bioética, presenta aspectos concernientes a la antropología, la teología, la ética y la procreación. El documento inicia de forma muy expresa y afirma que 
[...] desde la concepción hasta la muerte natural, se le debe reconocer la dignidad de persona. Este principio fundamental, que expresa un gran "sí" a la vida humana, debe ocupar un lugar central en la reflexión ética sobre la investigación biomédica que reviste una importancia siempre mayor en el mundo de hoy. (Congregación para la Doctrina de la Fe, 2008, p. 5)

Por lo tanto, se puede expresar que la relación bioética y magisterio de la Iglesia, aunque pareciera que son adversas, están en función de buscar consolidar la diáfana defensa de la persona y su devenir en la historia.

La formación bioética de los futuros clérigos está en función de conocer el sentido que tienen los avances de la ciencia e investigación médica y con ello, hacer lo posible para que no estén en detrimento de la persona, ya que el ser humano en su realidad íntima, desde el momento de su concepción, debe ser tratado como persona (Cf. Congregación para la Doctrina de la Fe, 2008).

\section{Resultados}

El termino persona, que ha tenido gran influencia en las corrientes de pensamiento humanístico, es una noción que -a pesar de las contingencias históricas- se puede comprender como una "recreación representativa" del individuo.

Cada periodo de la historia configura su noción de persona y se esfuerza por caracterizarlo. En la antigüedad el término se relacionaba de manera arraigada al teatro con la personificación que hacia el actor en la puesta en escena; en la Edad Media se enlazó a la imagen de las personas Trinitarias y tuvo grandes implicaciones en los seres humanos. En la modernidad el racionalismo y empirismo generaron sus propias interpretaciones de acuerdo con sus líneas de pensamiento. La posmodernidad presentó una multiplicidad de horizontes paraa la definición; el siglo XX fue un momento de confrontaciones ideológicas que propició el nacimiento del personalismo como filosofía que centra su reflexión en la persona como fundamento humanístico con repercusiones en todos los ámbitos.

Aunque solo se puedan hacer aproximaciones al concepto de persona, es evidente que con el personalismo emergió una mirada profunda a la sustancialidad del individuo desde su ser personal como don y misterio en la exaltación de su propia dignidad.

La Iglesia no desconoce la realidad conceptual del ser persona, de su dignidad; en su enseñanza la tiene presente como preocupación esencial para su formación y enseñanza magisterial. Debido a lo anterior, en los ciclos filosóficos y teológicos los contenidosantropológicos resultan relevantes para ayudar a tomar conciencia del ser y de la tarea de direccionar la vida de acuerdo con principios doctrinales y humanos.

\section{Conclusión}

Postular una definición sobre el concepto de persona resulta una tarea difícil, sin embargo, se logró aproximar a un concenso de significación cuyo resultado es vislumbrar definiciones que encierran los aspectos más importantes que caracterizan lo que es la persona y su dignidad. Al realizar un reccorido por la historia, esta presenta los principales postulados dados por las corrientes de pensamiento y representantes sobre lo que significó la persona en aquel momento específico.

El concepto de persona es una elaboracion eclesial. Esta se da gracias a las discusiones sobre la Trinidad en la época Medieval, lo que facilita entender mejor la conceptualización de “dignidad de la persona", puesto que el término se aplicó en pos de definir el misterio cristológico. 
La definición más importante que atraviesa todo el pensamiento Medieval es la que aportó Severino Boecio y que asevera que "la persona es una sustancia individual de naturaleza racional". Para él, la sustancialidad de la persona se establece en la racionalidad que esta posee y que la identifica en su individualidad. Se puede decir que la definición de Boecio es la base que sustenta todas las definiciones sobre persona y que parte de la postulación antropológica, al igual que todas las corrientes de pensamiento y teóricos del tema.

Los procesos de formación de los aspirantes al sacerdocio están enmarcados en una fuerte noción humanística que no desconoce la postulación de las ciencias humanas en esta preocupacion. La Iglesia fundamentó un currículo formativo que ahonda en todas las dimensiones del hombre en aras de llegar a la persona completa, por

\section{Referencias}

Barrio Maestre, J. (2007). Cómo formar la segunda naturaleza. Notas antropológicas acerca de la educación de los hábitos. Estudios sobre educación, 7-23.

Boluarte Drago, A. (2018). La persona humana en lavisión antropológica de Karol Wojtyla. PHAINOMENON, 97-104.

Burgos, J. (2013). Antropología: una guía para la existencia. Madrid: Palabra.

Ciccone, L. (2006). Bioética. Historia. Principios. Cuestiones. Madrid: Palabra.

Congregación para la doctrina de la fe. (2008). Dignitas personae. Sobre algunas cuestiones de bioética. Bogotá: Paulinas. lo que la ayuda de la filosofía, la psicología, la antropología y la bioética supusieron gran beneficio en esta tarea.

No se puede desconocer el aporte de la filosofía personalista para la clarificación conceptual de la noción de persona, inspirado en la visión que de ella se dio desde el ámbito eclesial. Esta corriente de pensamiento otorga al individuo el valor absoluto porque la persona es el punto central y neurálgico para la explicación de cualquier realidad.

El personalismo presenta al invividuo como un ser relacional, trascendente y abierto, con capacidad de reconocimiento y de reconocer, lo que va más allá de cualquier ideología que cosifica y reduce al individuo. Es por ello que la formación sacerdotal recoge todos los argumentos sobre la persona y con ellos busca clarificar el sentido de su dignidad, además de presentar los elementos en pro de su defensa.

Farrel, G. (1991). Liberalismo, Iglesia y nuevo Orden. Buenos Aires: Ediciones del Encuentro.

Ferrater Mora, J. (2002). Diccionario de filosofía. $K-P$. Barcelona: Ariel.

Ferrater Mora, J. (2002). Diccionario de filosofia. Tomo III (K-P). Barcelona: Ariel.

Gafo, J. (2003). Bioética teológica. Madrid: Desclée De Brouwer.

Goñi, C. (2010). Brave historia de la filosofía. Madrid: Palabra.

Hertling, L. (2006). Historia de la Iglesia. Barcelona: Herder.

León, F. (2011). Bioética. Madrid: Palabra. 
Lepargneur, H. (2008). Bioética, nuevo concepto. El camino del consenso. Bogotá: Paulinas.

Lleras, P. (2019). Personalismo y Tomismo. La razón historica, 22-49.

Martín Hernández, F., \& Martín de la Hoz, J. (2014). La formación sacerdotal. Historia y vida. Madrid: San Pablo.

Masiá, J. (2008). Bioética y religión. Madrid: Sintesis.

Pele, A. (2015). Kant y I Dignidad Humana. Revista Brasileira de Estudos Politicos, 15-46.

Prats Mora, J. (2012). La forma cristiana de educar. Valencia: Edicep.

Ramos Rosere, C. (2015). Hombre, persona y dignidad. Metafísica y persona. Filosofía, conocimiento y vida, 103-119.

Ries, J. (1994). Los ritos de iniciación. Bilbao: EGA.

Rovetta Kliver, F. (2008). El descubrimiento de los derechos humanos. Madrid: IEPALA.

Ruiz Romám, C. (2010). La educación en la sociedad postmoderna. Desafios y oportunidades. Revista Complutense de Educación, 21(1), 173-188.
Sala Balust, L., \& Hernández Salamanca, F. M. (1966). La formación sacerdotal en la Iglesia. Barcelona: Selecciones gráficas.

Sánchez García, J. (2016). La persona humana y sus perspectiva antropológica. FIDES ET RATIO, 77-104.

Sarmiento, A. (1987). El don de la vida. Documentos del Magisterio de la Iglesia sobre Bioética. En J. P. II, Donum vitae (págs. 475-522). Madrid: BAC.

Sgreccia, E. (2013). Persona humana y personalismo. Cuadernos de Bioética, 115-123.

Tomás y Garrido, G., \& Postigo Solana, M. (2007). Bioética personalista: Ciencia $y$ controversias. Madrid: Ediciones Internacionales Universitarias.

Yacarini-Martínez, A. (2019). La bioética personalista en la formacion universitaria. El aporte cientifico de S.E.R. Elio Sgreccia. Revista Vida y ética, 81-88.

Zavala Olalde, J. (2010). La noción general de persona. El origen, historia del concepto y la noción de persona en grupos indigenas de México. Revista de Humanidades: Tegnológico de Monterrey, 293-318. 